\title{
Editorial
}

\section{Rotator cuff tears and shoulder impingement: a tale of two diagnostic test accuracy reviews}

Helen Handoll, Nigel Hanchard, Mario Lenza \& Rachelle Buchbinder 07 October 2013

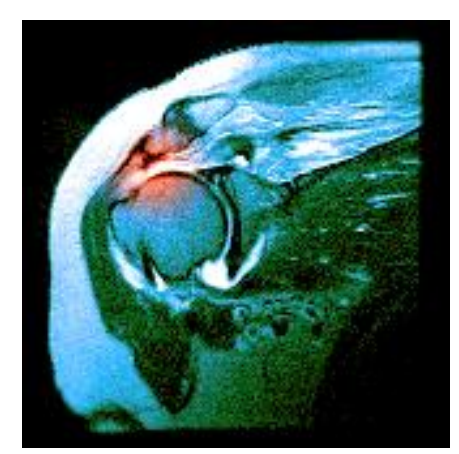

A recently published diagnostic test accuracy (DTA) review evaluates magnetic resonance imaging (MRI), magnetic resonance arthrography (MRA) and ultrasonography for assessing rotator cuff tears in people with shoulder pain for whom surgery is being considered.[1] Tears in the rotator cuff, a group of tendons and muscles that surrounds the shoulder, cause pain and may impair shoulder stability and movement. They are often graded as impartial thickness' or 'full thickness'. The review compares the three index tests with assessment during surgery, usually arthroscopic (keyhole) surgery. Arthroscopy is an imperfect reference test, with all the disadvantages inherent in surgery as well as between-rater variation in the classification of tears.[2]

The main finding of the review is that MRI, MRA, and ultrasonography have good and similar diagnostic accuracy for the detection of fullthickness tears in the population studied.[1] Nonetheless, as quantified in the review, some full thickness tears will be missed, and some people will be offered unnecessary surgery should full-thickness tears be the main indicator. The less-evidenced findings for any rotator cuff tear (combined results for full- and partial thickness tears) are worth spelling out: "In a population of 100 people with shoulder pain suspected of having a rotator cuff tear and for whom surgery is being considered, if the prevalence [of any rotator cuff tear] was $80 \%$ [median prevalence of 
studies in comparison], investigation with MRI may miss two cases (2/80, $3 \%)$, while investigation with ultrasonography may miss seven cases (7/80, 9\%). Among patients without a rotator cuff tear (20 out of 100), four patients tested using MRI may have a rotator cuff tear wrongly detected (4/20, 20\%) and may undergo unnecessary surgery. A similar number (3/20, 15\%) may be over-treated if ultrasonography is used. "[1]

These findings are sobering in the context of the poor evidence for effectiveness and safety of surgical treatment of rotator cuff disease.[3] A further 'elephant in the room' is that asymptomatic rotator cuff tears are common.[4] Lastly, although Lenza et al restricted their review to prospective studies, they stressed that the strength of evidence for all test comparisons was limited. In only six of the 20 included studies was it clear that there was "an adequately representative spectrum of consecutive patients from secondary or tertiary care", the target population of the review.

The DTA review focusses on the small subset of people being considered for surgery, but most people with shoulder pain are diagnosed and managed in the primary care setting, and recent guidelines do not advocate imaging for shoulder pain in primary care unless serious pathology is considered.[5-7] Usually MRI or MRA assessment, and consideration for surgery, should be considered at a late stage of a care pathway, after demonstrated failure to improve with conservative treatment, which might include medication for pain, glucocorticoid (steroid) injection, or physiotherapy.

Disabling shoulder pain is a common reason to seek medical care, and primary care clinicians should be alert to the causes. Rotator cuff tendon problems, including tears, may present with features of impingement (pinching) of the rotator cuff tendons or subacromial bursa as the arm is moved in certain directions. In addition to the patient history, there are a plethora of physical tests that may be useful. These tests are examined in another DTA review, published earlier this year.[8] This review purposefully focussed on primary care and included 33 generally poorquality studies, only two of which recruited any patients from primary care. The remaining studies were judged as not meeting the criteria for having a representative spectrum of patients, mainly reflecting the use of surgery as a reference test; the prevalence of symptomatic rotator cuff 
tears is likely to be far higher in patients who are referred for consideration of surgery. The review concluded that there was insufficient evidence upon which to base selection of physical tests to detect impingement and associated pathologies, in primary, secondary, or tertiary care. The extreme diversity in the performance and interpretation of the physical tests in these studies hindered synthesis of the evidence and the clinical applicability of the findings. In addition, few studies addressed the key issue of between-rater agreement, which is fundamental to the validity of clinical tests.

Hanchard et al's Cochrane Review offers tentative guidance to the primary care clinicians faced with an impingement-related disorder.[8] The first step may be to screen for large rotator cuff tears and other conditions that are likely to warrant surgical opinion, so that a timely referral is made, but to implement a trial of conservative treatment in the interim. This advice seems sensible because most people with rotator cuff tears improve with conservative treatment, although the recovery process can be protracted. The identification of optimal conservative treatment is, however, hampered by a lack of a terminology to define shoulder complaints and the mixed populations of many of the trials testing conservative interventions for shoulder pain.[9]

The two Cochrane Reviews highlighted here report on key methods of assessment at the early and late stages of the clinical pathway for rotator cuff disorders.[1,8] Both note the unsatisfactory nature of the evidence to inform diagnostic decisions, a deficiency mirrored in the findings of intervention reviews. There is clearly a lot to be done to improve outcomes for this common condition.

\section{Author information}

Helen HG Handoll ${ }^{1}$, Nigel CA Hanchard ${ }^{2}$, Mario Lenza ${ }^{3}$ and Rachelle Buchbinder ${ }^{4}$ ${ }^{1}$ Helen HG Handoll (h.handoll@tees.ac.uk), Senior Research Fellow, Health and Social Care Institute, Teesside University, Middlesbrough, UK, and Co-ordinating Editor, Cochrane Bone, Joint, and Muscle Trauma Group; ${ }^{2}$ Nigel CA Hanchard (n.hanchard@tees.ac.uk), Senior Research Fellow, Health and Social Care Institute, Teesside University, Middlesbrough, UK, and Editor, Cochrane Bone, Joint, and Muscle Trauma Group; ${ }^{3}$ Mario Lenza (mariolenza@yahoo.com.br), Orthopaedic Surgeon, Department of Orthopaedics and Traumatology, Federal University of São Paulo, Brazil, and Editor, Cochrane Bone, Joint, and Muscle Trauma Group and Cochrane Musculoskeletal Group. ${ }^{4}$ Rachelle Buchbinder (rachelle.buchbinder@monash.edu), 
Director, Monash Department of Clinical Epidemiology, Cabrini Hospital, and Professor, Department of Epidemiology and Preventive Medicine, Monash University, Melbourne, Australia, and Joint Co-ordinating Editor, Cochrane Musculoskeletal Group.

\section{How to cite}

Helen Handoll, Nigel Hanchard, Mario Lenza \& Rachelle Buchbinder. Rotator cuff tears and shoulder impingement: a tale of two diagnostic test accuracy reviews[editorial]. Cochrane Database of Systematic Reviews 2013;(10): 10.1002/14651858.ED000068

\section{References}

1. Lenza M, Buchbinder R, Takwoingi Y, Johnston RV, Hanchard NCA, Faloppa F. Magnetic resonance imaging, magnetic resonance arthrography and ultrasonography for assessing rotator cuff tears in people with shoulder pain for whom surgery is being considered. Cochrane Database of Systematic Reviews 2013;9:CD009020. dx.doi.org/10.1002/14651858.CD009020.pub2

2. Spencer EE, Dunn WR, Wright RW, Wolf BR, Spindler KP, McCarty E, et al. Interobserver agreement in the classification of rotator cuff tears. American Journal of Sports Medicine 2007;35(3):437-41. dx.doi.org/10.1177/0363546507307504

3. Coghlan JA, Buchbinder R, Green S, Johnston RV, Bell SN. Surgery for rotator cuff disease. Cochrane Database of Systematic

Reviews 2008;1:CD005619.dx.doi.org/10.1002/14651858.CD005619.pub2

4. Rees JL. The pathogenesis and surgical treatment of tears of the rotator cuff. Journal of Bone and Joint Surgery (British Volume) 2008;90(7):827-32.dx.doi.org/10.1302/0301-

\section{X.90B7.19874}

5. Australian Acute Musculoskeletal Pain Guidelines Group. (2003) Evidence-based management of acute musculoskeletal pain. Brisbane: Australian Academic

Press. www.nhmrc.gov.au/_files_nhmrc/publications/attachments/cp95.pdf (access ed 19 September 2013)

6. Geraets JJ, de Jongh AC, Boeke AJP, Buis PAJ, Spinnewijn WEM, Geijir RMM, et al. [Summary of the practice guideline for shoulder complaints from the Dutch College of General Practitioners]. Nederlands Tijdschrift voor Geneeskunde 2009;153:A164.

7. Bussières AE, Peterson C, Taylor JA. Diagnostic imaging practice guidelines for musculoskeletal complains in adults--an evidence-based approach: introduction. Journal of Manipulative and Physiological Therapeutics 2007;30(9):617-

83. dx.doi.org/10.1016/j.jmpt.2007.10.003

8. Hanchard NCA, Lenza M, Handoll HHG, Takwoingi Y. Physical tests for shoulder impingements and local lesions of bursa, tendon or labrum that may accompany impingement. Cochrane Database of Systematic

Reviews 2013;4:CD007427 dx.doi.org/10.1002/14651858.CD007427.pub2

9. Green S, Buchbinder R, Hetrick SE. Physiotherapy interventions for shoulder pain. Cochrane Database of Systematic

Reviews 2003;2:CD004258dx.doi.org/10.1002/14651858.CD004258

Competing interests: The authors have completed the ICMJE form for disclosure of potential conflicts of interest (forms available on request) and declare that they are coauthors of Cochrane Reviews discussed in this editorial: diagnostic tests for assessing 
rotator cuff tears (reference 1; ML, RB, NH); surgery for rotatior cuff disease (reference 3;

$\mathrm{RB}$ ); and physical tests for shoulder impingements (reference 8; $\mathrm{NH}, \mathrm{ML}$ and $\mathrm{HH}$ ).

\section{Image credit}

Medical Body Scans/Science Photo Library

\section{Keywords}

- Diagnosis

- Orthopaedics \& trauma

\section{Feedback}

Please contact David Tovey, Cochrane Library Editor in Chief, with feedback on this editorial and proposals for future editorials. 